$\underline{\text { Iranian Journal of Pathology | ISSN: 2345-3656 }}$

\title{
Herpes Simplex Virus and Langerhans Cell Histiocytosis
}

\author{
Maliheh Khoddami ${ }^{1}$, Seyed Alireza Nadji ${ }^{2}$, Paria Dehghanian ${ }^{3 *}$ \\ 1. Pediatric Pathology Research Center, Research Institute for Children Health, Shahid Beheshti \\ University of Medical Sciences, Tehran, Iran \\ 2. Virology Research Center (VRC), National Research Institute of Tuberculosis and Lung Diseases \\ (NRITLD), Shahid Beheshti University of Medical Sciences, Tehran, Iran \\ 3. Pediatric Infections Research Center, Research Institute for Children Health, Shahid Beheshti University \\ of Medical Sciences, Tehran, Iran
}

\begin{tabular}{c}
\hline KEYWORDS \\
\hline Histiocytosis \\
Langerhans-Cell \\
Herpes Simplex Virus \\
Polymerase Chain reaction \\
Cell Proliferation \\
\\
\hline Article Info \\
\hline
\end{tabular}

Received 14 Des 2015;

Accepted 29 Jan 2017;

Published Online 2017;

\section{ABSTRACT}

Background and objective: Langerhans cell histiocytosis (LCH) is a rare histiocytic proliferative disorder of unknown etiology and mainly affects young children. The histological feature is granuloma-like proliferation of langerhans-type dendritic cells. Although the possible role of viruses such as Epstein-Barr virus (EBV, Human Herpes virus -4), Human Herpes virus-6 (HHV-6), Herpes Simplex virus (HSV) types 1 and 2 and Cytomegalovirus (CMV, Human Herpes virus-5) is suggested in the pathogenesis of LCH by some investigators, its exact pathophysiology has not been cleared yet. In this study, we investigated the presence of $H S V$ types 1 and 2 in Iranian children with $\mathrm{LCH}$

Methods: In this retrospective study, we investigated the prevalence of presence of $H S V$ types 1 and 2 (in 30 patients with $\mathrm{LCH}$ ), using paraffin-embedded tissue samples and 30 age and tissue-matched controls (operated for reasons other than infectious diseases) from the Department of Pediatric Pathology, Tehran, Iran, by nested Polymerase Chain reaction method. No ethical issues arose in the study, because only the pathology reports were reviewed and patients were anonymous.

Results: We failed to find $H S V$ types 1 and 2 DNA in any of the 30 patients with LCH or the control group.

Conclusion: According to our findings, $H S V$ types 1 and 2 do not appear to have any etiologic role in the pathogenesis of $\mathrm{LCH}$ in Iranian children. These results are in accordance with previous investigations with negative findings.

Corresponding information: Paria Dehghanian, MD, Pediatric Infections Research Center, Shahid Beheshti University of Medical Sciences, Tehran, Iran. E. mail: Paria_email@yahoo.com.

Copyright (C) 2017, IRANIAN JOURNAL OF PATHOLOGY. This is an open-access article distributed under the terms of the Creative Commons Attributionnoncommercial 4.0 International License which permits copy and redistribute the material just in noncommercial usages, provided the original work is properly cited.

\section{Introduction}

Langerhans cells are a type of non-lymphoid mononuclear cells involved in inflammatory responses; $\mathrm{LCH}$ is the neoplastic proliferation of these cells, the clonality of which was first reported by in 1994 (1-3). These immature dendritic cells express lysosomal enzymes CD1a, cytoplasmic S100 protein, langerin (CD207) and contain the racket shaped organelles of Birbeck granules on electron microscopy (4-6).

LCH is an enigmatic histiocytic proliferative disease of unknown etiology; however, a possible etiologic link between viruses or vaccination and LCH has been proposed among other environmental agents $(7,8) . E B V$ is known as the etiologic agent of several malignancies and Herpes viruses are reported to cause persistent infections $(9,10)$. In addition, hemophagocytic syndromes in human with several inherited immunodeficiency types are proposed to be induced by $C M V$ (11-13). Controversial results are reported in the literature regarding the etiologic role of HHV-6 (14-19). Although no positive result is reported regarding 
$H S V(14,17,18)$, the etiologic role of $H S V$ is yet to be determined. Accordingly, in this study, we investigated the possible association of $H S V$ types 1 and 2 and LCH in Iranian children.

\section{Materials and Methods}

Patients and Controls

Formalin-fixed, paraffin-embedded (FFPE) tissue samples of 30 patients with pathologic diagnosis of LCH were extracted from the archive of Pathology Department of Mofid Children's Hospital in Tehran, Iran (one of the national referral centers) for a 10-year period (2002-2012). Diagnosis of LCH was made by a pediatric pathologist, using the histological criteria mentioned in the pathology textbooks, i.e. granulomas composed of Langerhans cells with typical grooved nuclei mixed with eosinophils and other inflammatory cells. The diagnoses were confirmed using immunohistochemical technique for CD1a, S-100 protein and CD68 when available. After examination of slides by light microscopy, tissues with adequate amount of tumoral tissue were used in the study and those with too small tumors were excluded. All patients were Iranian and age ranged between 2 months and 10 years. Thirty tissue samples with non-LCH diagnoses, who were operated for reasons other than infectious diseases, were also selected from the files of the Pathology Department (between the years 2002 and 2012), as controls (age and tissue-matched to LCH cases). These patients were operated for reasons such as hemangioma, cystic hygroma, osteochondroma, dermatitis, emphysema, pilonidal disease, soft tissue cysts, enlarged reactive nodes, anal fissure, etc. The inclusion criterion of tissue in control group was absence of clinical and microscopic evidence for LCH or any other tumor.

\section{Paraffin-Embedded Tissue Section Preparation and DNA Extraction}

The $5 \mu \mathrm{m}$-thick- tissue sections were cut from paraffin-embedded blocks on a microtome and put into sterile screw-cap tubes. It is necessary to completely remove the embedding material before DNA extraction. The xylene and alcohol solutions were used to deparaffinization and rehydration of the tissue sections. For this purpose, the section- contained tubes were heated in dry oven at $55-60^{\circ} \mathrm{C}$ for 5 minutes, positioned so as to allow drainage of melting paraffin. Then Xylene $(1 \mathrm{~mL})$ was added to the tubes and incubated at room temperature for two minutes. The tubes were centrifuged at high speed and Xylene was discarded. This was repeated once more in fresh xylene for one minute. For washing and rehydration, $1 \mathrm{~mL}$ of $100 \%, 95 \% 70 \%$ ethanol timely were added to the tubes for two minutes. Then the sections were immersed in 1X PBS for two minutes. The PBS was discarded from tube by centrifugation and pipetting.

Then the sections were lysed by a tissue lysis buffer (containing EDTA $0.05 \mathrm{mM}$-Tris $0.01 \mathrm{mM}$ SDS $0.2 \%$; pH 8.0) and Proteinase K (5 mg /ml). The samples were subjected to DNA extraction when the tissues were dissolved. DNA was extracted from the lysed-tissue sample according to the company's instructions $\left(\mathrm{RTP}^{\circledR}\right.$ DNA/ RNA Virus Mini Kit Procedure; Stratec Molecular, Berlin, Germany). The extracted nucleic acids were stored at $-20^{\circ} \mathrm{C}$ before performing PCR.

\section{Polymerase Chain Reaction}

The quality control of the extracted DNA was performed using SYBR Green Real-time PCRMelting curve for beta globin gene using GH20 primer; GAAGAGCCAAGGACAGGTAC and PCO4 primer; CAACTTCATCCACGTTCACC (Figure 1).

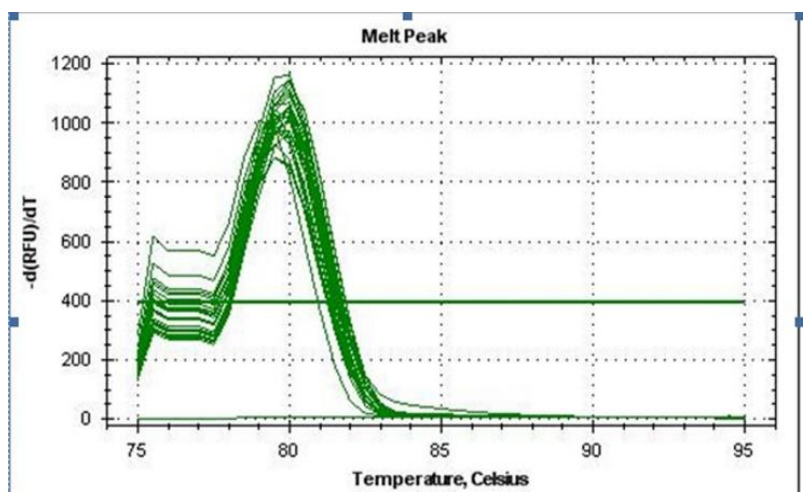

Figure 1. Beta-globin gene SYBR Green Real-time PCR-Melting curve. The melting temperature of Betaglobin PCR product is around $82.5^{\circ} \mathrm{C}$. 
The Thermo Scientific ${ }^{\mathrm{TM}}$ Maxima ${ }^{\mathrm{TM}} \mathrm{SYBR}^{\mathrm{TM}}$ Green 2X qPCR Master Mix and 10 pmol per reaction of the $\mathrm{GH} 20 / \mathrm{PCO} 4$ primers were used to conduct the quality control.

To detect $H S V-1 / 2$, two sets of nested-PCR were applied to detect $H S V-1 / 2$ genomes in the samples as described before (20). The primer sequences are as below: HSV1F1 ATCRCGGTAGCCCGGCCGTGTGACA; HSV1R1 CATACCGGAAGCCACCACACAA; HSV2F1 TCAGCCCATCCTCCTTCGGCAGTA; HSV2R1 GATCTGGTACTCGAATGTCTCCG; HSV1F2 CATAYCGACCACACCGACGA; HSV1R2 GGTAGTTGGTCGTTCGCGCTGAA; HSV2F2 AGACGTGCGGGTCGTACACG; HSV2R2 CGCGGTCCCAGATCGGCA. By using the gpD HSV-1/2 sequence primer sets, the 140 and 100 bp fragments came positive for $H S V-1$ and $H S V-2$, respectively (Figure 2).

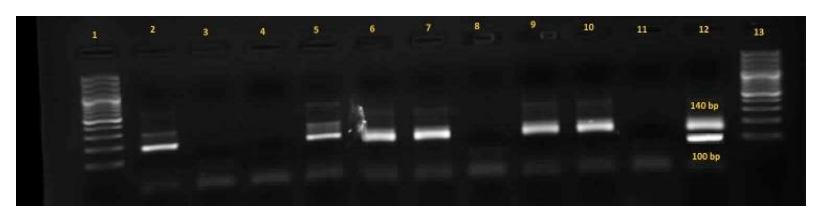

Figure 2. The gel electrophoresis picture of HSV1/2 nested PCR assay. The 140 and $100 \mathrm{bp}$ bands are related to HSV1 and HSV2 positive cases, respectively. Lanes 1 and 13: 100bp DNA size marker; lanes 2 to 10: clinical samples; lane 11: negative control of PCR and lane 12: positive control of HSV detection kit.

The limit detection of 50 genome copies of $H S V-1 / 2$ per reaction was determined by the nested PCR assays using serial dilutions of AmpliRun® HSVI, HSV2 DNA CONTROL (Vircell, Spain). The positive clinical samples and the Vircella DNA control were used as positive controls in our assay.

\section{Statistical and Ethical Considerations}

Data was analyzed using Chi-Square or Fisher's exact test. $\mathrm{P} \leq 0.05$ was considered to indicate statistical significance.

In this study, no ethical issues were involved. Only the pathology reports were reviewed retrospectively and patients were anonymous.

\section{Results}

Thirty patients with a pathologic diagnosis of LCH were included in this study. All patients were Iranian (16 male and 14 female) and the age ranged between 2 months and 10 years. Age, sex and biopsy site of all patients are shown in Table 1. Thirty tissue samples with non-LCH diagnoses were also selected as controls (age and tissue-matched to LCH cases). HSV DNA was not detected in any of $30 \mathrm{LCH}$ patients or in the control group (Table 1).

Table1. Age, Sex and Biopsy Site of Patients

\begin{tabular}{|cc|}
\hline Age (years) & $\mathbf{2 . 9 6} \pm \mathbf{2 . 5 5}$ \\
\hline Gender & $14(46.67 \%)$ \\
\hline Female & $16(53.33 \%)$ \\
\hline Male & \\
\hline Biopsy site & $10(33.33 \%)$ \\
\hline Soft tissue & $7(23.33 \%)$ \\
\hline Bone & $4(13.33 \%)$ \\
\hline Soft tissue and Bone & $7(23.33 \%)$ \\
\hline Skin & $1(3.33 \%)$ \\
\hline Lymph node & $1(3.33 \%)$ \\
\hline Lung &
\end{tabular}

\section{Discussion}

Considering the fact that LCH could have an etiologic association with viruses, as suggested by previous studies $(7,8,14,15,19)$, this study was conducted due to the lack of information about such a possible link in Iranian children in English medical literature.

It is proposed that the direct oncogenic mechanism of HSV-1 and 2 is by induction of unscheduled DNA synthesis. Both viruses have an anti-apoptotic activity in lytically infected cells, particularly HSV-2 protein ICP10PK, which inhibits apoptosis through activation of Ras/Raf1/MEK/ERK Pathway. HSV1 was associated with prostate cancer, melanoma and cervical cancer and was detected in benign and malignant thyroid tumors (21).

LCH (histiocytosis X) is an uncommon disease with three overlapping clinical syndromes which includes multifocal multisystemic LCH (LettererSiwe disease), multifocal unisystemic LCH (HandSchüller -Christian disease) and unifocal LCH (solitary eosinophilic granuloma) (2). Hematoxylineosin stain of biopsy slide shows granulomas composed of a mixture of Langerhans cells, macrophages, eosinophils, multinucleated giant 
cells and lymphocytes $(3,4)$. The involved organs and age determine the prognosis of $\mathrm{LCH}$. Children usually need treatment, whereas most adult patients with lung involvement have an indolent course of regression $(5,6,22,23)$.

Although some investigators have tried to seek a link between viruses and $\mathrm{LCH}$, they have failed to report any positive results for many viruses including $H S V$ (16-18).

Jeziorski et al. (16) demonstrated no significant association between $E B V, C M V$ or $H H V-6$ in the pathogenesis of LCH. On the contrary, Leahy et al. (14) detected $H H V-6$ in $47 \%$ of 30 patients with $\mathrm{LCH}$, but their cases had negative results for $H S V$ using PCR technique. Glotzbecker et al. (15) used the immunohistochemistry method (IHC) and in situ hybridization (ISH) for detection of $H H V-6$ and reported a high rate of $71.4 \%$ by both methods. However, they reported no significant difference between patients with $\mathrm{LCH}$ and the control group in their study on 13 patients with $\mathrm{LCH}$, using qualitative and quantitative real-time PCR (24). Csire and colleagues (19) had a LCH patient with persistent $H H V-6$ detection through 17 years of follow up and suggested that $H H V-6$ infection may be associated with development or progression of $\mathrm{LCH}$.

Concerning HSV, McClain et al. (17) used sensitive ISH and PCR techniques in 56 cases of $\mathrm{LCH}$ and found no positive results. In their review of the literature, McClain et al. (18) did not find any positive reports regarding $H S V$ in $\mathrm{LCH}$. We also failed to find the $H S V$ type 1 and 2 DNA in either of the $\mathrm{LCH}$ patients, which is in concordance with some other results reported in the literature $(14,17$, 18).

In previous studies (14-19) authors declared no limitations and the methods used included serology, IHC, ISH and PCR. However, IHC and ISH for HSV were not available for us, which is considered as the main limitation of our study.

\section{Conclusion}

Our investigation was the first study performed in Iran on this subject. Our negative result for $\mathrm{HSV}$ $1 / 2$ is similar to previous studies in the literature $(14,17,18)$. Performing such studies could be of importance, because vaccination or an early diagnosis and treatment of viral infections could prevent development of $\mathrm{LCH}$ in the future.

\section{Acknowledgement}

This study was conducted as a dissertation by Dr. Paria Dehghanian under the supervision of Dr. Maliheh Khoddami, to fulfill the requirements for Pediatric Pathology Fellowship at Shahid Beheshti University of Medical Sciences, Tehran, Iran.

This study was financially supported by the Pediatric Infections Research Center, Research Institute for Children Health, Shahid Beheshti University of Medical Sciences, Tehran, Iran.

We thank Dr. Ahmad Reza Shamshiri (Epidemiologist, Assistant Professor, Dental Research Center, Dentistry Research Institute, Department of Community Oral Health, School of Dentistry, Tehran University of Medical Sciences, Tehran, Iran), for statistical analysis, Ms. Leila Poos-Ashkan and Pooneh Tavakoli (Virology Research Center, National Research Institute of Tuberculosis and Lung Diseases (NRITLD), Shahid Beheshti University of Medical Sciences, Tehran, Iran) for performing the PCR, and Mojgan Shohadai (Deparment of Pathology, Mofid Children's Hospital, Shahid Beheshti University of Medical Sciences, Tehran, Iran) for technical assistance.

\section{Conflicts of interest}

Authors had no conflicts of interest to be reported.

\section{References}

1. Willman CL, Busque L, Griffith B, Favara BE, McClain KL, Duncan MH, et al. Langerhans' cell histiocytosis (histiocytosis X): A clonal proliferative disease. New Engl $J$ Med 1994;331(3):154-60.

2. Weiss LM. Histiocytic and dendritic cell proliferations. In: Knowles DM, editor. Neoplastic Hematopathology. $2^{\text {nd }}$ ed. Philadelphia: Lippincott Williams \& Wilkins; 2001. P. 1815-45.

3. Lichtenstein L. Histiocytosis X; integration of eosinophilic granuloma of bone, Letterer-Siwe disease, and Schuller-Christian disease as related manifestations of a single 
nosologic entity. AMA Arch Pathol1953;56(1): 84-102.

4. French Histiocytosis study group. A multicentre retrospective survey of Langerhans' cell histiocytosis: 348 cases observed between 1983 and 1993. The French Langerhans' Cell Histiocytosis Study Group. Arch Dis Child 1996;75(1): 17-24.

5. Ladisch S. Langerhans cell histiocytosis. Curr Opin Hematol1998; 5(1): 54-8.

6. Laman JD, Leenen PJ, Annels NE, Hogendoorn PC, Egeler RM. Langerhans-cell histiocytosis 'insight into DC biology'. Trends Immunol 2003; 24(4):190-6.

7. Chen CJ, Ho TY, Lu JJ, Sheu LF, Lee SY, Tien $\mathrm{CH}$, et al. Identical twin brothers concordant for Langerhans' cell histiocytosis and discordant for Epstein-Barr virus-associated hemophagocytic syndrome. Eur J Pediatr 2004;163(9): 536-9.

8. Sakata N, Toguchi N, Kimura M, Nakayama M, Kawa K, Takemura T. Development of Langerhans cell histiocytosis associated with chronic active Epstein-Barr virus infection. Pediatr Blood Cancer 2008;50(4):9247.

9. Purtilo DT. Epstein-Barr-virus-induced oncogenesis in immune-deficient individuals. Lancet 1980;1(9):300-3.

10. Young LS, Rickinson AB. Epstein-Barr virus: 40 years on. Nat Rev Cancer 2004; 4(10):757-68.

11. Hertel L, Lacaille VG, Strobl H, Mellins ED, Mocarski ES. Susceptibility of immature and mature Langerhans cell-type dendritic cells to infection and immunomodulation by human cytomegalovirus. J Virol 2003;77(13): 7563-74.

12. Lee AW, Hertel L, Louie RK, Burster T, Lacaille V, Pashine A, et al. Human cytomegalovirus alters localization of MHC class II and dendrite morphology immature Langerhans cells. J Immunol 2006;177(6): 3960-71.

13. Senechal B, Boruchov AM, Reagan JL, Hart DN, Young JW. Infection of mature monocyte-derived dendritic cells with human cytomegalovirus inhibits stimulation of T-cell proliferation via the release of soluble CD83. Blood 2004;103(11):4207-15.

14. Leahy MA, Krejci SM, Friednash M, Stockert SS, Wilson H, Huff JC, et al. Human herpesvirus 6 is present in lesions of Langerhans cell histiocytosis. $J$ Invest Dermatol 1993;101(5):642-5.

15. Glotzbecker MP, Carpentieri DF, Dormans JP. Langerhans cell histiocytosis: a primary viral infection of bone? Human herpes virus 6 latent protein detected in lymphocytes from tissue of children. $J$ Pediatr Orthop 2004;24(1):123-9.

16. Jeziorski E, Senechal B, Molina TJ, Devez F, Leruez-Ville M, Morand P, et al. HerpesVirus Infection in patients with Langerhans Cell Histiocytosis: A Case-Controlled SeroEpidemiological Study, and In Situ Analysis. PLoS One 2008;3(9):e3262.

17. McClain K, Jin H, Gresik V, Favara B. Langerhans cell histiocytosis: lack of a viral etiology. Am J Hematol1994;47(1):16-20.

18. McClain K, Weiss RA. Viruses and Langerhans Cell Histiocytosis: Is there a Link? $\mathrm{Br}$ J Cancer 1994;70 (Suppl. XXIII):S34-6.

19. Csire M, Mikala G, Jákó J, Masszi T, Jánosi J, Dolgos J, et al. Persistent long-term human herpesvirus 6 (HHV-6) infection in a patient with langerhans cell histiocytosis. Pathol Oncol Res 2007;13(2):157- 60.

20. Aurelius E, Johansson B, Sköldenberg B, Forsgren M. Encephalitis in immunocompetent patients due to herpes simplex virus type 1 or 2 as determined by type-specific polymerase chain reaction and antibody assays of cerebrospinal fluid. J Med Virol 1993;39(3):179-86.

21. Alibek K, Baiken Y, Kakpenova A, Mussabekova A, Zhussupbekova S, Akan M, et al. Implication of human herpesviruses in oncogenesis through immune evasion and suppression. Infect Agents and Cancer 2014, 9:3.

22. Ninaber M, Dik H, Peters E. Complete pathological resolution of pulmonary langerhans 
cell histiocytosis. Resp case reports 2014; 2(2):76-8.

23. Berber I, Erkurt MA, Kuku I, Koroglu M, Kaya E, Unlu S. A rare disease in adult: Langerhans cell histiocytosis. World J Oncol 2013;4(3):165-8.
24. Glotzbecker MP, Dormans JP, Pawel BR, Wills BP, Joshi Y, Elkan M, et al. Langerhans cell histiocytosis and human herpes virus 6 (HHV-6), an analysis by real-time polymerase chain reaction. J Orthop Res 2006;24(3):313-20.

\section{How to Cite This Article:}

Khoddami M, Nadji SA, Dehghanian P. Herpes Simplex Virus and Langerhans Cell Histiocytosis. Iran J Pathol. 2017;12(4):323-28. 